\title{
Agro é pop: os caminhoneiros de Na Estrada no contexto do "novo rural brasileiro"
}

\section{Denise Tavares}

\section{Resumo}

Este trabalho analisa Na Estrada - Vida de

Caminhoneiro, do Canal Rural, buscando demonstrar

os sentidos do programa e suas estratégias de

linguagem em duas temporadas distintas. Também

busca averiguar como o projeto relaciona-se com

determinadas matrizes do imaginário assumidas pela

mídia televisiva sobre o meio rural e que diálogos

estabelece com o movimento de valorização do

agronegócio no contexto do novo rural brasileiro.

Em "Na Estrada", o foco no caminhoneiro retrabalha

características do "road movie" e busca atualizar

o discurso do Brasil desconhecido "que dá certo".

Reforça, assim, uma visão homogênea e esquemática do campo, mantendo sua realidade complexa distante da percepção do mundo urbano.

\section{Palavras-Chave}

Televisão. Na Estrada - Vida de Caminhoneiro. Agronegócio

\section{Denise Tavares}

Doutora em Integração Latino-Americana - USP, São Paulo. Professora do Departamento de Comunicação Social e Coordenadora do Programa de Pós-Graduação em Mídia e Cotidiano da Universidade Federal Fluminense - UFF (Niterói, Rio de Janeiro, Brasil). Coordena também o Grupo de Pesquisa MULTIS - Núcleo de Estudos e Experimentações do Audiovisual e Multimídia (CNPq). Universidade Federal Fluminense (Niterói, Rio de Janeiro, Brasil). E-mail: denisetavares51@gmail.com

\section{Introdução}

No início de outubro de 2016, a Rede Globo de

Televisão iniciou uma campanha publicitária cujo slogan era Agro é tech, Agro é pop, Agro é tudo. Criada pelas gerências de Marketing e Comunicação da emissora, a campanha apresentava vídeos de 50 segundos sobre produtos do agronegócio, valorizando a importância desse setor para a economia do país, inclusive referindo o quanto geraria de empregos. Segundo informações no site do Grupo (G1, 03/10/2016) à época, a proposta seria veicular esses vídeos até junho de 2018, ou seja, 0 ano da próxima eleição presidencial no Brasil. Assim, revestida, segundo ela, da intenção de mostrar à população das cidades e do campo o quanto 0 agronegócio é fundamental ao país, a maior rede de televisão brasileira e a com maior audiência, utilizando seu canal aberto e vários outros que acumula no cabo, coloca no ar por quase dois anos, nas emissoras da sua rede, onde e quem representa "o melhor do Brasil", na sua visão.

Robert Schmidt, diretor de marketing da TV Globo, ao justificar a criação da campanha esclareceu 
que esta tinha como objetivo compartilhar com todos os brasileiros a versão de que 0 agronegócio vive hoje um cotidiano marcado pela tecnologia ${ }^{1}$. A pretensão é a de que cabe à mídia construir uma nova percepção da realidade rural brasileira, modificada por esse setor "que é tudo". Conceitualmente, o sistema agro incorpora a produção (incluindo fornecimento de insumos), a distribuição e o consumo (MENDES; PADILHA Jr, 2007), expandindo, assim, o território rural ${ }^{2}$. Tratase de um desenho geo-sócio-econômico, de onde destacamos a figura do caminhoneiro, personagem que funciona como "ponte" entre os dois mundos, pois, quase sempre morador da cidade, trabalha com a circulação e o escoamento da produção agrícola e agrária do país. Nesses percursos, atravessa 0 "Brasil profundo", tornando-se uma espécie de olheiro privilegiado e provavelmente capaz de identificar as diversas mazelas que persistem nesses locais do território nacional. Esses e outros atributos parecem ter inspirado ${ }_{0}$ Canal Rural - que se autodenomina o maior representante do agronegócio brasileiro - a criar a série Na Estrada - Vida de Caminhoneiro, cujos 26 episódios foram exibidos em 2015 e 2016 e continuam sendo reapresentados. Além disso, as duas temporadas estão disponíveis no site do
Rural, e parte delas também pode ser encontrada no YouTube.

Documental, a série ecoa a pretensão do agronegócio de ampliar sua popularidade, configurando um protagonismo assentado no investimento de singularizar um sistema de produção articulado por uma cadeia com muitos nós invisíveis para boa parte da população brasileira. É um movimento que abre brecha no majoritário jornalismo de prestação de serviço do Canal Rural, conforme dados que levantamos no percurso de construção da pesquisa que gerou este texto, quando nos foi útil, também, verificar um conjunto de reflexões acadêmicas acerca das matrizes do imaginário midiático brasileiro sobre o meio rural. Estas ajudaram a compreender as articulações narrativas e estéticas do Programa, que, ao tentar romper com o modelo da grande reportagem, fabulouse inspirado no ideário midiático que envolve a figura do caminhoneiro no país, tantas vezes emoldurada por uma apresentação que margeia o mito do herói, em versão banalizada da construída por Campbell (1989). Além disso, quando percorre estradas, esse protagonista também agrega valores de um dos gêneros mais

Disponível em http://www.startagro.agr.br/por-que-o-agronegocio-precisa-de-uma-comunicacao-moderna/ - (Acesso em 12 de maio de 2017).

Este é um conceito amplo. Não explicita, por exemplo, os diferentes tipos de produtores. Vale esclarecer que 0 artigo trabalha, genericamente, com a identificação dos grandes proprietários rurais como sinônimos do agronegócio.

Expressão ambígua que, entre outras versões, significa os lugares distantes dos grandes centros urbanos do país habitados por um povo solidário e trabalhador (ALVES, 2003) ou representa, metaforicamente, as regiões rurais nas quais se preservam as relações de poder pautadas pelo coronelismo (SANTOS, 2013). Apesar destas variações, a imprensa, quase sempre, torna sinônimo "Brasil profundo" e sertão do país. 
férteis do audiovisual moderno: o road movie e seus ideais de vida livre, com potencial de encontros inesperados que proporcionam, não raro, o reencontro de si mesmo.

Tal amálgama norteia nossa hipótese de que as duas temporadas do programa procuram criar um "caso" praticamente sincrônico ao ideário do agronegócio que desfraldou a necessidade de uma comunicação "moderna". Isto é, o programa cria a suspeita de um paradoxo pois, sob o propósito da "modernidade" (na versão sinônima de tecnologia), o desafio é apresentá-la sem esgarçar as positividades que prevalecem no imaginário sobre 0 campo, em especial sua natureza pacífica e capacidade de trabalho que, na versão do agro, realinha o país à estrada do desenvolvimento ${ }^{4}$, garantindo-lhe futuro. Neste sentido, Na Estrada - Vida de Caminhoneiro arrisca uma empreitada que procura não só diferenciar o programa em termos de linguagem, estética, formato e temática do conjunto da produção do Canal Rural, como também busca estabelecer diferenças em relação a outros projetos em que o caminhoneiro é central, tais como Pé na estrada ${ }^{5}$, veiculado pela Rede Bandeirantes, e Brasil caminhoneiro ${ }^{6}$, pelo Sistema Brasileiro de Televisão, SBT. Isso ocorre porque, nessas duas produções, a linha editorial limita-se à circunscrição do protagonista para, assim, servi-lo, apontando condições de estrada, oportunidades de trabalho, oficinas e mesclando essas informações a referências do seu universo cultural.

As distinções balizam o nosso interesse em compreender como as duas temporadas do Canal Rural, focadas no caminhoneiro, negociam os referenciais do jornalismo, da linguagem televisiva e da distensão das fronteiras do gênero com as estratégias que mobilizam 0 agronegócio em seu investimento em comunicação. 0 esforço analítico considera, com Aumont e Marie (2004), a importância da segmentação e da interpretação, com ênfase na análise temática e de conteúdo não ortodoxa, que incorpora a problemática da narrativa e da voz no audiovisual de não-ficção

Trata-se de uma ideologia que se nutre de diversas fontes, sendo uma das mais significativas no cenário contemporâneo 0 INAE - Instituto de Altos Estudos. Criado em 1991 por João Paulo dos Reis Velloso, ex-ministro do Planejamento (1969-79), ele dá caráter jurídico e institucional ao Fórum Nacional, evento anual iniciado em 1988 com o apoio do IBMEC (Instituto Brasileiro de Mercado de Capitais) e cuja edição de 2012 apontava o Agronegócio como um dos pilares para o país sair da crise (VELLOSO, 2012).

5 programa é resultado da parceria da revista 0 Carreteiro, que circula desde 1970, com a Trucão Comunicações, de Pedro Trucão, radialista que, também nos anos 1970, criou o Trucão e os Caminhoneiros do Brasil, na Rádio Iguatemi, de Osasco, SP e que é diretor do programa de TV, cuja duração é de 30 minutos. Segundo o site de Pé na Estrada, seu foco principal é "a valorização do profissional da estrada". (Fontes: http://www.penaestrada.com.br; http://www.ocarreteiro.com.br/ e http:// trucao.com.br/. Acessos em março e abril de 2017).

Inicialmente, o programa era denominado Siga Bem Caminhoneiro, quando foi exibido por mais de 13 anos no SBT a partir de maio de 1995. A mudança de nome e de rede (para a Banda) aconteceu em 2009. Após dois anos, voltou ao SBT, agora sem alterar a nova identificação, Brasil Caminhoneiro. Também foca na prestação de serviços ao profissional de estrada, abrindo-se, ainda, ao universo cultural que o envolve. 0 programa integra um sistema de comunicação de mesmo título, que agrega programa de rádio de mesmo nome, o Jornal do Agro e site. (Fonte: http://brasilcaminhoneiro.com.br/. Acessos em março e abril de 2017). 
(NICHOLS, 2005). A abordagem plurimetodológica demanda do locus do objeto, território desenhado por operações investigativas que incluíram, em segunda etapa ${ }^{7}$, o mapeamento da comunicação audiovisual do agronegócio. Nessa delimitação encontramos, como já colocado, a prevalência da prestação de serviços, a valorização do desenvolvimento tecnológico no campo, do discurso de formação e, em alguns casos, de relativa abertura ao gênero musical sertanejo (na versão atualizada).

A angulação aqui explorada apresenta-se, neste texto, dividida em três partes. Primeiro, vamos localizar, brevemente, certo percurso das matrizes do imaginário sociocultural brasileiro sobre 0 mundo rural por avaliar que essa trajetória sedimenta nosso olhar sobre Na Estrada - Vida de Caminhoneiro, que se vale de um processo de significação construído midiaticamente. Em seguida, apresentamos o Canal Rural e seu desenho de programação e como ocupa a internet na sua versão de TV Online. 0 objetivo é contextualizar, rapidamente, essa relação do canal com o agronegócio. Finalmente, focamos nas duas temporadas do programa, que elege como protagonistas os caminhoneiros, discutindo sua formatação, estrutura narrativa e os diálogos que estabelece com seu contexto de produção, linguagem audiovisual e as referências ao imaginário rural, conforme já apontadas anteriormente. Em função do limite de espaço, optamos por abordagem que enfatiza as marcas identitárias da proposta. Esta exalta, em seu discurso de apresentação, estar acompanhando a história de "caminhoneiros reais transportando cargas reais".

\section{Imaginários sobre o rural no audiovisual}

Do ponto de vista dos estudos sociológicos sobre 0 campo e cidade, ou sobre o rural e 0 urbano, até meados dos anos 1930 consolidou-se uma abordagem que, inspirada nos estudos de Ferdinand Tönnies, quase sempre considerava esses espaços como bem distintos e até mesmo antagônicos, especialmente em termos sociais e culturais (BLUME, 2004). |Tal posição balizou um imaginário de antagonismo cultural bastante ancorado pelos meios de comunicação de massa, a partir do cinema e o rádio e, mais tarde, também encontrando na televisão um espaço acolhedor. Esse desenho de posições opostas, no caso do rural, privilegiou como protagonista um "caipira" que, quando em trânsito pela cidade, mantinha profícua ingenuidade que era, na maioria das

A primeira etapa deste projeto de pesquisa ocorreu em 2014 e 2015, com apoio do CNPq, quando construímos uma cartografia da produção de não ficção sobre meio ambiente na América Latina. Como um de seus desdobramentos, focamos a representação do rural, considerando, particularmente, os principais embates entre dois territórios que consideramos demarcados pelo confronto político, isto é, o Agronegócio e a Agroecologia. Ambas abarcam uma diversidade de atores, o que ampliou, significativamente, a sistematização dos seus dados. A opção de pesquisa foi, então, desenhar os campos a partir dos principais antagonismos que envolvem a posse da terra e a crítica aos sistemas de cultivo. No entanto, é preciso mencionar que o Agronegócio também se apresenta, em diversos momentos, como engajado nos princípios da agroecologia, assumindo, entre outros, 0 discurso da sustentabilidade. 
vezes, apenas aparente. Ou seja, uma postura que se revelava, ao longo das narrativas, estratégia inteligente e/ou esperta de sobrevivência deste homem rural, diante da agressividade e do desdém da cultura da cidade em relação ao modo de vida e aos valores deste personagem e também ao seu meio de origem.

Um exemplo matriz desse modelo é o filme "Nhô Anastácio Chegou de Viagem”, comédia de 1908, de Julio Ferrez, considerada por Vicente de Paula Araújo uma forte candidata ao título de primeira ficção cinematográfica brasileira. 0 enredo, nesta fita de cerca de 15 minutos, narrava as aventuras "de um matuto que veio passear no Rio de Janeiro, desembarcou na Estação da Central, andou pelas ruas, viu a caixa de conversão, entrou no Palácio Monroe, visitou o Passeio Público, enamorou-se de uma cantora, mas tudo se complicou com a chegada súbita da esposa" (GONZAGA; SALLES, 1966, p. 16). Com direito a final feliz e muitas cenas de perseguição, o filme conquistou grande público sem se tornar protótipo imediato, já que os sucessos cinematográficos seguintes concentraram-se mais em temas de crimes e melodramas inspirados na literatura, além dos chamados filmes cantantes.
Anos depois, no entanto, as representações do caipira ingênuo/esperto vão encontrar nos personagens criados por Amacio Mazzaropi, ator e cineasta nascido em 1912, em São Paulo, provavelmente a sua melhor tradução. Diretor de mais de 30 filmes $^{8}$, Mazzaropi, filho de pai imigrante italiano e mãe portuguesa, passou a infância no Vale do Paraíba, especialmente em Tremembé, na casa do avô materno, tocador de viola e dançarino, que o leva a conhecer a cultura caipira. Essa vivência, reunida às experiências que teve quando viajava com um circo pelo interior do Brasil, seria fonte de inspiração para o diretor que também chegou a atuar no teatro e no rádio. Mas foi no cinema, especialmente a partir de "Jeca Tatu", filme de 1959 e maior bilheteria do ano, que ele consolidou sua versão de caipira no imaginário popular do país (DAHER, 2013). 0 roteiro da obra é baseado na versão reformulada de Monteiro Lobato, criador do personagem $^{9}$ que, no cinema de Mazzaropi, ganha trejeitos, prosódia e vestuário - calças "pula-brejo", paletó apertado, camisa xadrez e botinas - que continuam referência para a composição de papéis similares, especialmente na teledramaturgia nacional.

0 primeiro filme de Mazzaropi foi "Sai da Frente", de 1952, e o último, o "Jeca e a égua milagrosa”, em 1980. Após sua morte, em 1981, Mazzaropi começou a ser reconhecido pela intelectualidade brasileira, uma postura que ganhou fôlego e se consolidou a partir dos anos 1990.

A primeira vez em que Jeca Tatu aparece na obra de Lobato é em Urupés (1918) em que, em chave polêmica, o autor credita ao personagem ser símbolo da preguiça e das impossibilidades de um Brasil melhor. No entanto, 0 autor reformula sua posição e passa a aderir, fortemente, às campanhas de saneamento básico nacional, diagnosticando Jeca Tatu com ancilostomose (doença popularmente conhecida como "amarelão"), devido às precariedades das suas condições de vida, o que mobiliza um médico a tratá-Io. A ciência, portanto, muda a vida do personagem. 
Outra abordagem midiática sobre o rural vem dos documentários sobre o campo, em especial os realizados por Humberto Mauro no Instituto Nacional de Cinema Educativo (INCE) ${ }^{10}$. São obras que buscam consolidar um imaginário de sabedoria e valores positivos da vida rural brasileira, com ênfase na placidez dos cenários e na integração cotidiana do homem à natureza, em diapasão bem diferenciado e distante das comédias populares ${ }^{11}$. Norteia tal produção a percepção do cineasta de que o país passava por progressiva mudança, o que trazia risco objetivo de desaparecimento do modo de vida e cultura oriundos do meio rural (TAVARES, 1999). Tal modelo mantém-se quase intacto na televisão, que chegou ao Brasil em 1950 e teve grande expansão nos seus primeiros vinte anos no país. A TV, assim como ocorreu em reportagens das revistas ilustradas que circularam nos anos $1970^{12}$, manteve a idealização do mundo rural, valorizando a biodiversidade brasileira e seus fenômenos naturais, apresentados sempre como excepcionais. "No Brasil, nessa perspectiva idílica, que remete à visão mitológica sobre o paraíso, tanto a Amazônia, o Cerrado, a Caatinga, os Pampas e outras paisagens naturais de beleza reconhecida são retratados pelos media como lugares encantados, carregados de mistérios, lendas e mitos"

(BARROS, 2015, s/p).

Também, e talvez ainda mais marcadamente, podem ser inseridas, neste quadro idealizado, as telenovelas, que, quando se debruçam sobre rural, têm quase sempre trabalhado na perspectiva de encantamento, de paisagens plácidas e acolhedoras, de personagens ingênuos - algumas vezes tendendo ao cômico -, além de manterem a possibilidade de ascensão social colada na mais forte tradição do folhetim, ou seja, na relação amorosa entre classes sociais distintas. No caso, entre o fazendeiro e a camponesa ou vice-versa. Exemplos destas escolhas abundam, especialmente nas telenovelas de Benedito Ruy Barbosa que, conforme Pereira, citando Machado e Becker (2008), cravou na teledramaturgia nacional, com a novela Pantanal, exibida pela Rede Manchete em 1990, uma "reorientação da tessitura audiovisual, no gênero telenovela, tendo a natureza como recurso cenográfico" (PEREIRA, 2015, p. 2).

Enfim, com este sintético arrolamento, 0 que queremos evidenciar é a prevalência das tipificações positivas que perduraram no imaginário midiático audiovisual sobre 0

10 O INCE foi criado por Getúlio Vargas em 1936 e tornado departamento do Instituto Nacional de Cinema a partir de 1967. Seu primeiro diretor foi Roquette Pinto. A proposta central do órgão era utilizar o cinema como auxiliar do ensino, visando à educação popular. (TAVARES, 1999).

11 Entre elas pode-se destacar a série Brasilianas: canções populares, iniciada em 1945 por Mauro, e outros filmes de temática rural do mesmo diretor, como João de Barros, de 1956; A Velha a Fiar, de 1964 e Carro de boi, de 1974. (TAVARES, 1999).

12 É preciso ressalvar a revista Realidade, da Editora Abril, lançada em 1966, cujas grandes reportagens assumiam perspectiva crítica bastante diferenciada, por exemplo, de Manchete e Cruzeiro, duas das maiores revistas de circulação desses anos. 
mundo não urbano, a despeito de, a partir da década de 1980, o meio rural brasileiro vivenciar outras mudanças significativas em função, especialmente, da introdução "de uma maior diversificação econômica, em meio a novas formas de produção e subsistência, em visível contraste com o que dominava no passado" (REIS, 2006, p. 2). A nova situação, para 0 autor, implica, entre outras questões, uma revisão das definições dicotômicas do que seja rural e urbano, recuperando, por exemplo, estudos como os de Sorokin \& Zimmermann, que, desde 1929, introduziram o conceito do "continuum rural e urbano" (op. cit., p.6 - grifo do autor). A abordagem, apesar de manter uma perspectiva de oposição, abre caminho para que outros pesquisadores mais tarde assumam o conceito, por considerarem que, na nova realidade da organização espacial de países como o Brasil, há uma enorme dificuldade de delimitar o que é rural e o que é urbano, situação que dialoga com 0 discurso do agronegócio, e que, na década de 1990, é reforçada pelos dados apresentados pela pesquisa coordenada por Graziano da Silva e Hoffman.

Intitulada "Projeto Reurbano - Caracterização do Novo Rural Brasileiro, 1992/98”, entre outros diagnósticos, a pesquisa indicou, em sua primeira e segunda fase ${ }^{13}$, que as atividades na área rural brasileira já não se restringiam àquelas relacionadas à agropecuária e à agroindústria, incorporando, também, atividades de turismo e lazer, além de oferecerem uma série de serviços, tais como hotéis e restaurantes (SILVA, 1997). Ou seja, há nuances e variações que não são incorporadas pelos meios de comunicação de massa, conforme Barros (2015). Para ele, o que se mantém é uma abordagem esquemática que trabalha apenas em duas chaves: a idealizada, como exposto até agora, e a degradada. Esta última, ainda segundo o autor, seria resultante de situações vinculadas à preocupação internacional quanto às situações das florestas brasileiras, especialmente a Amazônica:

Em 1998, ocorreu um dos incêndios que chamariam a atenção do mundo, pelo ângulo mediático. As chamas arderam em Roraima. Enquanto a floresta queimava, governo, jornalistas de diversos países, pesquisadores, bombeiros, voluntários, curiosos, telespectadores, caciques, agricultores familiares se perguntavam como um incêndio daquelas proporções era possível. 0 que aconteceria com 0 verde da Amazônia e seus povos da floresta? Que implicações este incêndio teria para a camada de ozônio, para 0 efeito estufa, para liberação de carbono na atmosfera? As respostas vieram de todos os lados, e palavras como "meio ambiente", "ecologia" e "proteção ambiental" receberam os mais diversos e, algumas vezes, contraditórios sentidos. (BARROS, 2015, s/p)

Tais interrogações alinhavam o argumento conclusivo do autor de que à mídia interessa o caráter episódico dos acontecimentos relacionados ao campo, seja na versão idealizada, seja na degradada. Neste sentido, a mídia não atua na perspectiva de uma revisão da 
percepção pública quanto aos lugares de conflito que ocupam os grandes produtores rurais, os movimentos sociais ligados à disputa da terra, como, por exemplo, o MTST (Movimento dos Trabalhadores Sem Terra) e/ou a atuação das ONGs que se posicionam neste cenário. Isto é, por serem raramente abordados em sua ampla complexidade pelas emissoras brasileiras, esses conflitos em torno da posse da terra e das disputas de áreas de produção que permeiam a realidade rural do país acabam representados sob uma fórmula esquemática e espetacular, a despeito dos números trágicos que ostentam. Essa é uma realidade de comunicação que a campanha da Rede Globo, citada inicialmente, expressa, bem como a ênfase das últimas pautas do seu Globo Rural ${ }^{14}$. Identifica-se, assim, uma sintonia harmônica entre a grande mídia e 0 agronegócio, observado aqui como uma das expressões econômicas mais bem-sucedidas das camadas ricas do Brasil. Trata-se de uma riqueza que não só se apoia em parceiros essenciais na Comunicação, mas que tem procurado, também, investir em voz própria, como tem se assumido o Canal Rural, que afirma em seu site ser 0 "maior representante do Agronegócio brasileiro". A emissora está disponível no sistema a cabo e no sinal aberto das parabólicas ${ }^{15}$.

\section{Um representante do Agronegócio}

0 Canal Rural iniciou suas atividades em 11 de novembro de 1996, integrado à Globosat, programadora pertencente ao Grupo Globo, que conta hoje com 33 canais $^{16}$. Dois anos depois, 0 Rural passou para o Grupo RBS, do sul do país, 0 que 0 fez mudar sua sede de São Paulo para Porto Alegre. Já em 2013, foi novamente vendido, agora à holding J\&F Investimentos ${ }^{17}$, que controla 0 grupo JBS (avaliado como o maior frigorífico no setor de carne bovina no mundo). Segundo o presidente da emissora, Donário Lopes, em entrevista que marcou os 20 anos do Canal Rural ${ }^{18}$, este cresceu junto com 0 agronegócio e agora ostenta uma programação que combina entretenimento, informação e também formação do homem do campo. Em sua plataforma on-line, lançada em

Criado em 1980, o programa jornalístico passou por diversas formulações e apresentadores, chegando, inclusive, a ser diário. Hoje, é apresentado nas manhãs de domingo, e a linha editorial privilegia pautas do agronegócio, serviço, valorização da cultura tradicional rural e, eventualmente, publica matéria com teor de proteção ambiental. É possível acessar a produção do Programa no site G1. Já no endereço está explicitada a relação atual do Globo Rural com o agronegócio. (Verificar em: http://g1.globo.com/economia/agronegocios/index.html).

150 Canal é veiculado pela NET (185) SKY (159) OI (179), Claro (185) e também por parabólica, como colocado.

16 Dados do Coletivo Intervozes (http://brazil.mom-rsf.org/br/destaques/concentracao/. Acesso em 25/01/2018).

17 Holding criada em 1953 e que está hoje em mais de 30 países. Desde 2016, esteve envolvida em diversos escândalos financeiros que incluem fraudes e irregularidades envolvendo o BNDES e políticos brasileiros.

18 Disponível em http://www.canalrural.com.br/videos/canal-rural-20-anos/canal-rural-anos-evoluimos-com-agro-dizpresidente-emissora-75945. (Acesso em dezembro de 2016). 
2011 com a promessa de disponibilizar todo 0 conteúdo do Canal, a programação foi agrupada por editoria: Canal Rural (expediente, prestação de serviços, vendas e contato com 0 internauta); Notícias (com foco no Empreendedor e abordando, separadamente, 14 produtos do Agronegócio); Opinião (Blogs e abordagens temáticas como Campo \& Saúde, em um total de 30 "subcanais"); Especiais (séries e reportagens, onde está o Na Estrada); Informação (canais de teor político e econômico, tais como Bancada Rural, e mais outros sete "subcanais"); Técnicos (cursos e conteúdos de serviços com 12 "subcanais") e, finalmente, Entretenimento (variados, com oito "subcanais").

Outra frente criada pelo Rural é 0 Canal Rural $\mathrm{X}$, cuja programação é exibida de segunda a sexta-feira das $6 \mathrm{~h}$ às $12 \mathrm{~h}$ e é focada, conforme informações do site, na formação qualificada do produtor e do trabalhador rural. Veicula, ainda, o que considera os clássicos do acervo do Canal Rural. As produções do Rural X são resultantes de parceria com a Confederação da Agricultura e Pecuária do Brasil (CNA) e com o Serviço Nacional de Aprendizagem Rural (SENAR), que integra 0 Sistema $S^{19}$ há 20 anos. Lançado em 22 de junho de 2016, tendo como slogan "Ver, Rever, Aprender", o Rural X, com transmissão via parabólica (e também disponível Online), tem no Programa Senar seu "carro-chefe" e, segundo o então presidente da CNA (Confederação da Agricultura e Pecuária do Brasil), João Martins, é um importante meio para massificar o conhecimento para um público estimado de cinco milhões, do qual, segundo ele, três milhões têm renda inferior a meio salário mínimo: "Nosso objetivo é criar uma nova classe média no Brasil no meio rural, e só será possível se disseminarmos conhecimento a esses produtores" ${ }^{\prime 20}$, comentário que, por um lado, passa ao largo das condições de trabalho no meio rural brasileiro e, por outro, mostra-se afinado aos resultados da pesquisa de Graziano, que citamos anteriormente. A colocação também pode ser vista como um desdobramento da política de crescimento do Canal Rural, que investiu em um modelo de negócios que combinou relação com os grandes representantes do agronegócio brasileiro e atuação local circuito que envolve o pequeno e médio produtor. Um dos exemplos que explicita a estratégia é a busca de parceiros comerciais a partir de eventos organizados em locais onde o Rural ancora uma carreta equipada com sala de vídeo, que serve de auditório, e ali promove encontros a partir de temas comuns, como soja, por exemplo, ou oferece palestra de profissionais que focam mercado, novas tecnologias para o campo etc.

19 Integrado por nove entidades, o sistema é sustentado por dinheiro arrecadado pelo governo por meio de impostos de valor variados da indústria e comércio. Um estudo profundo do sistema foi realizado pelo senador Ataídes Oliveira, disponível para download em http://www2.senado.gov.br/bdst/handle/id/513503.

20 Fonte: http://www.canalrural.com.br/noticias/noticias/canal-rural-chega-produtores-todo-brasil-veja-comosintonizar-62590 (Acesso em 13/02/2017). 
A atuação soma-se ao fato de ser a TV segmentada a que mais atrai a audiência dos profissionais da agropecuária, de acordo com pesquisa do Ipsos Marplan (2013) ${ }^{21}$, a despeito do formato exibido na televisão ser 0 antigo standart ( 4 × 3), 0 que indica que 0 sistema de transmissão da emissora ainda não foi atualizado. A frente de definição da programação do Rural é de cinco ou seis dias, e as produções do Canal são definidas, quase todas, em janelas de 30 ou 15 minutos; apenas o Leilão Virtual de Gado (que cobre mais de 400 leilões por ano) e o TV Verdade (programa de debates sobre temas polêmicos) ficam no ar por três horas. Outras produções diferenciadas, com uma hora de janela para exibição, são o Arte Brasil, focado na divulgação do artesanato nacional, e o Giro do Boi, que abarca a produção, logística e as mais variadas informações sobre 0 gado no Brasil e no mundo. Já o Na Estrada, iniciado em 2009 graças à parceria do Canal com a MAN Latin America $^{22}$, tem tempo de produção médio de 23 minutos, encaixando-se, portanto, nos espaços de 30 minutos para exibição na TV. A proposta inicial de $\mathrm{Na}$ Estrada foi apresentar o cotidiano da cadeia do agronegócio, em um formato que não ficasse prisioneiro da estrutura das reportagens jornalísticas. Segundo o diretor do programa,
Cássio Peres, em vídeo realizado pelo Canal, desde a primeira reunião de produção, sua expectativa era de estar em um projeto que iria inovar o modo como o Rural trabalhava o jornalismo $0^{23}$.

A primeira temporada do Programa, quando ainda se intitulava apenas Na Estrada, foi apresentada em 12 episódios identificados pelas cadeias do setor, tais como trigo, suco de laranja, frutas do vale São Francisco, cacau, hortaliças etc. 0 tempo de produção foi de dois meses - setembro a novembro de 2009. A equipe era formada pelo repórter Gustavo Bonato, o cinegrafista Cristiano Mazoni e o motorista e auxiliar técnico Eduardo Ongaro. Eles percorreram um total de $17.500 \mathrm{~km}$ em um caminhão da Volkswagen, identificado com o logo do programa e do Canal Rural. 0 percurso foi iniciado no Rio Grande do Sul e concluído no Pará, após atravessar oito estados brasileiros. A equipe destacou a Transamazônica como o trecho mais difícil do trabalho, em função das péssimas condições da estrada, com muitos buracos. Já a logística da produção, concentrada em Porto Alegre naquele momento, apontou que 0 maior desafio era a necessidade de encontrar personagens que "rendessem" histórias interessantes para servirem como "pano

21 Fonte: http://portfoliodemidia.meioemensagem.com.br/portfolio/midia/CANAL+RURAL/26923/sobre (Acesso em 09/02/2017).

22 Empresa criada em 16 de março de 2009 a partir da compra da Volkswagen Caminhões e ônibus pela MAN SE (empresa mãe do Grupo MAN). Autodefine-se como a maior fabricante de caminhões e a segunda maior de ônibus da América Latina. Sua fábrica de montagem fica em Resende, cidade do Estado do Rio de Janeiro. (Fonte: https://www.man-la.com/ institucional/linha-do-tempo - Acesso em 08/02/2017).

23 Fonte: https://www.youtube.com/watch?v=WP5UeMRssPE (Acesso em 13/02/2017). 
de fundo" de cada episódio, no pouco tempo que tiveram para viabilizar o projeto. Avaliado como um sucesso pelo presidente do Canal Rural, que considerou que 0 caráter atemporal do projeto facilitava as reexibições, o $\mathrm{Na}$ Estrada teve cinco temporadas; as versões de 2015 e 2016 (a última até agora) ganharam uma especificidade: 0 foco no caminhoneiro. Assim, o programa passou a se chamar Na Estrada - Vida de Caminhoneiro.

\section{Na Estrada - Vida de Caminhoneiro}

A nova versão elege, como a especificidade do título expõe, um protagonista, o que produz uma primeira modificação substantiva na apresentação de cada episódio: a sinopse, agora, é centrada nas características deste personagem que é apresentado como herói brasileiro ao enfrentar as aventuras, dificuldades e perigos que rondam seu cotidiano na estrada - jornada cuja redenção será garantida pela entrega da carga no prazo estabelecido. Em termos dramáticos, a mudança concentrou a enunciação, o que, para a produção, significou refinar a seleção dos protagonistas, valorizando os que conseguissem portar-se de forma mais natural diante da câmera e também conseguissem se expor durante 0 percurso, estabelecendo um diálogo imaginário com o público, com direito a algumas quebras da "quarta parede" ${ }^{4}$. Tais falas são didáticas e buscam conduzir/explicar para o telespectador as situações vividas no dia a dia da viagem, incluindo digressões, que significam, quase sempre, autorreflexão sobre a própria vida. Esses discursos configuram áudios que preenchem os tempos mortos da narrativa e desvelam uma percepção de mundo bastante pautada pela visão idealizada da profissão e do mundo que a circunscreve, o que é reforçado pelo narrador fora-de-campo, estilo ancorado na tradição griersoniana que foi absorvida pelo jornalismo televisivo (NICHOLS, 2005).

0 viés informativo-didático, portanto, continua, a despeito do deslocamento do protagonismo que aloca subjetividade à temporada. Tratase de não investir, em demasia, em rupturas estéticas e/ou narrativas que criem suspeitas sobre a inscrição no real, pois é preciso manter 0 vínculo com o jornalismo televisivo, já que, como lembra Barreto (2013, p.68), a relação que este mantém "com os telespectadores é fundada em um acordo histórico em que estes autorizam 0 jornalismo a recolher fatos e temas que ocorrem no meio social para torná-los públicos”. Sob este horizonte, cada edição é iniciada com esse narrador onisciente que apresenta 0 caminhoneiro: nome, origem e anos de profissão. Singularizado, o personagem ganha imponência graças ao velho truque do enquadramento em ligeiro contraplongée, tendo ao fundo 0 companheiro de estrada, ou seja, seu caminhão. 
A dupla, assim imbricada, consolida uma idealização homem-máquina, já vista antes no audiovisual, em versões com motocicleta e carro, em que a ideia de liberdade é fabulada na versão que tipificou o road movie, gênero que "projeta a mitologia do Oeste Americano na paisagem transposta e ligada pelas estradas do país" (COHAN; HARK, 1997, p.1), e cuja consolidação tem como marco o período pós-guerra e a emergência de uma cultura masculina, sob crise familiar e identificada com os meios de transporte mecanizados. Seu (do gênero) paradigma basilar é dominar o espaço, o que o coloca imerso em um paradoxo: "ao mesmo tempo em que celebra um elemento pertencente à modernidade sólida (0 automóvel, a motocicleta), cristaliza o imaginário de liberdade em terras inóspitas, selvagens, promovendo a valorização da natureza em oposição à urbanização asfixiante" (TAVARES, 2009, p.
44). Essas características foram apropriadas por outras cinematografias e retrabalhadas em chaves identitárias distintas (PAIVA, 2008; TAVARES, 2009), algo que a televisão, em clivagem documental também fez, deslocando a viagem para o primeiro plano, como em programas de turismo, "mochilões" etc. 0 procedimento, no entanto, soterra as contradições e angústias dos personagens e valoriza a descoberta de territórios exóticos e exuberantes. A esse movimento, o Na Estrada não se esquiva, articulando um ideal de liberdade circunscrito ao encontro com a natureza, apresentada em tomadas de cartão postal e à distância do patrão, em subtexto que remete ao empreendedorismo, sem demarcar se essa é a realidade trabalhista do caminhoneiro. 0 programa também não deixa dúvidas de que o domínio espacial, neste caso, segue a rigidez de um percurso reproduzido em infográfico (Figura 1), eliminando, assim,

Figura 1: 0 infográfico é didático e valoriza o percurso do protagonista.

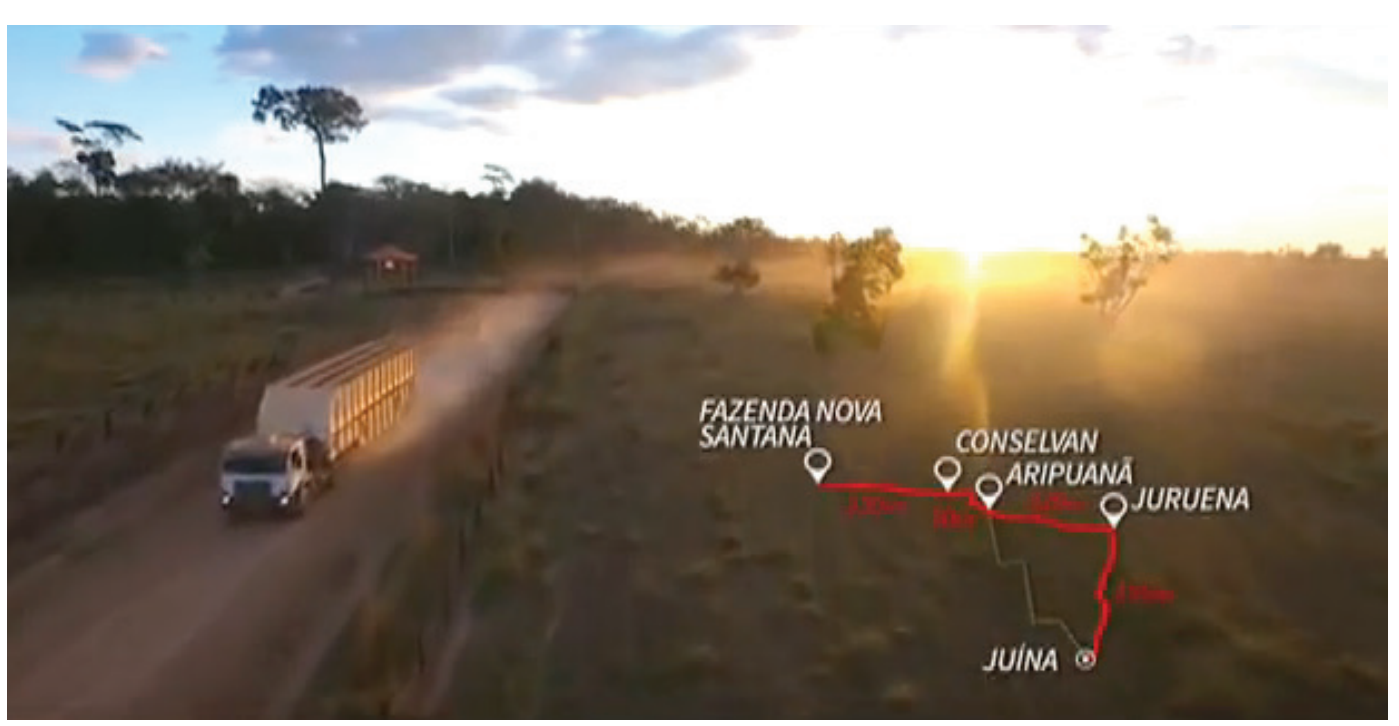


qualquer imaginário em torno de uma rota aberta, sem margens e sem destino.

Quanto à relação com a família, não há crise; ao contrário, principalmente esposa e filhos aparecem em vários episódios, em encontros marcados por muita emoção - situação que a câmera e a edição não rejeitam, corroborando a visão dos sacrifícios de uma vida pautada por longas ausências. 0 contraponto ao provedor generoso é oferecido pela escolha profissional, apresentada, em quase todos os episódios, como projeto de manter a tradição da família ou conquista de um desejo embalado por muitos anos, desde a infância. Por exemplo, no primeiro episódio da temporada 2015, protagonizado por Marcelo Krindges, depois de este verbalizar que seu amor pela profissão é justamente porque ela lhe oferece liberdade - "o que eu gosto mesmo é ficar na estrada", diz - 0 caminhoneiro de Santa Catarina localiza a opção profissional em seus sonhos de menino. A fala é aproveitada imageticamente pela narrativa: através de inserts de fotos do Krindges criança, fundamenta-se a estratégia biográfica, em procedimento já duramente criticado por Bourdieu (2006, pp.183184), para quem é equivocado articular fatos posteriores para garantir o sentido de uma história de vida. As fotos também reforçam o vínculo ao real ao mesmo tempo que ampliam o interesse pelo interstício da vida que não está ali exposta, desenhando a empatia necessária para que ocorra a identificação (com quem vive a profissão, seja direta ou indiretamente), e a valorização de um personagem que se reconhece potente, capaz de "conquista" e sem questionamentos extras em relação à situação de trabalho.

A idealização, moldada pelo reconhecimento do heroísmo de quem adentra os rincões do país para viabilizá-lo em sua melhor e mais digna faceta, permite acompanhar sem enfado os procedimentos anteriores à viagem, que garantem a segurança na estrada e confirmam o perfil do trabalhador atento, que acompanha toda a vistoria feita no caminhão registrada pela câmera. 0 detalhamento destaca a tecnologia sofisticada - e, portanto, moderna - e a relação de cada caminhoneiro com isso. A afinação com os interesses do patrocinador, integrante do sistema do agronegócio, incorpora entrevistas rápidas com funcionários da empresa, em uma mescla de estilos cada vez mais explorada nos produtos televisivos. 0 deslizamento estético não surpreende, já que, na "televisão contemporânea, não há uma distinção rígida entre informação e ficção" (BARRETO, 2013, p. 73). 0 contrato com o real, entretanto, é invólucro necessário e, neste sentido, a série tem o cuidado de ampliar o espectro de idade dos protagonistas (uma realidade da profissão no Brasil) e até mesmo de gênero, incluindo uma mulher como personagem central de um dos episódios (vamos retomar este tema mais adiante).

Em termos de estrutura, a narrativa busca equilibrar informação e subjetividade, apresentando-se como um "diário". 0 gênero 
permite alinhavar bem os indicadores dos dias e as distâncias percorridas. 0 efeito dramático resulta da antecipação de cada meta, ou seja, introduz 0 ponto que precisa ser atingido enquanto pontua 0 ritmo da narração, sempre muito dependente do protagonista. Cabe a ele elencar as dificuldades que surgem e dimensionar os perigos, em um jogo que aciona memórias de outras viagens, tais como pagar pedágio quando se atravessa área indígena (provavelmente um procedimento irregular), desviar de capivaras que atravessam a estrada inesperadamente ou enfrentar chuvas torrenciais que aumentam os já amplos buracos das rodovias. Em função desses discursos empreendidos entre os solavancos da cabine, cada caminhoneiro vai esgarçando sua visão de mundo em pequenos episódios que marcam sua trajetória na profissão, sua relação familiar e as histórias que valoriza. São estas, especialmente, que dialogam com as matrizes da cultura rural. Um destaque é a versão ingênua-cômica dos personagens que resgatam 0 caipira, como faz Marcelo Krindges quando explica 0 episódio que lhe rendeu o apelido de "MATAVACA ${ }^{25 " ~(F i g u r a ~ 2) ~ e m ~ f u n c ̧ a ̃ o ~ d e ~ u m a ~ s i t u a c ̧ a ̃ o ~}$ que ocorreu em sua primeira viagem como caminhoneiro, e de "delicado", por ter que entrar nas gaiolas da carroceria na ponta dos pés, para se desviar do gado. A referência preconceituosa surge entre gracejos, natural e amena, embalada em trilha alegre e emoldurada pela paisagem do espaço limpo de poluição e de conflitos, marcas de uma textualidade que aparentemente está se entregando, neste e em outros momentos, ao estilo observacional (NICHOLS, 2005).

Figura 2: 0 caminhoneiro Marcelo Krindges, o MATA-VACA

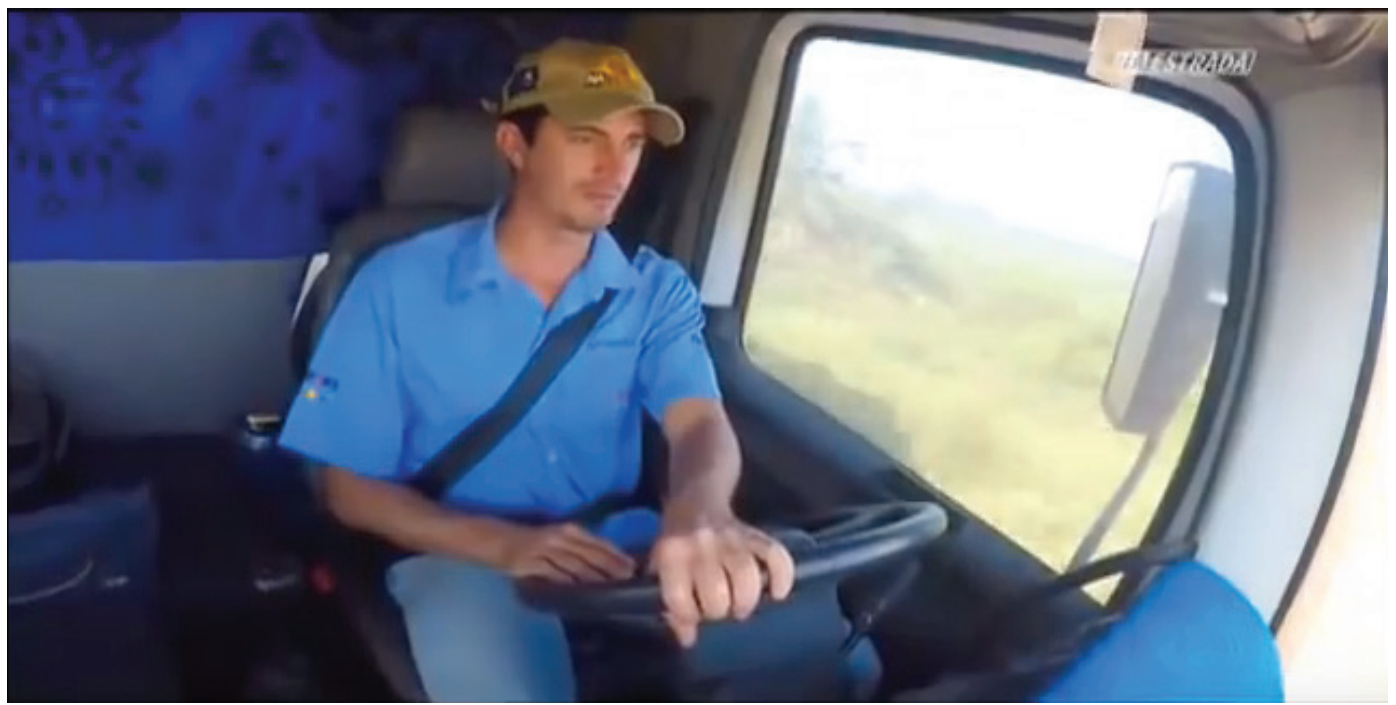

FONTE: Print do programa 
Mas, de fato, a produção nunca perde 0 controle e, neste sentido, as mudanças constantes de cenário facilitam a edição em sequências curtas e a intervenção de elementos discursivos que reforçam alguns clichês do ambiente rural, como um canto do galo ao amanhecer. Este se sobrepõe, assim como outros ruídos incidentais, a uma trilha musical que permanece na diegese praticamente durante todo o tempo do programa, em variações similares às empregadas em vinhetas de novela de temática rural. A sensação de déjà vu é reforçada pelos grandes planos aéreos que focam gado correndo - imagem que remete diretamente à novela $O$ Rei do Gado, da Rede Globo - e pelo esforço de encadear planos detalhes que valorizam a relação humanizada dos vaqueiros com 0 gado, postura admirada pelo caminhoneiro que naturalmente integra-se ao grupo. As referências sedimentam a legitimidade do protagonismo e arrumam estruturalmente a narrativa, diluindo os jogos de oposição e respaldando, paradoxalmente, as poucas sombras expostas. Uma delas vem de Mauro Ferreira Araújo, o CATAPORA, de 42 anos, que transporta soja. Ele é praticamente 0 único que ressalta negativamente a vida solitária e relata algumas tristezas oriundas da vida que escolheu ter. 0 tom sombrio dirige-se, também, ao ambiente da BR 163, via que percorre sedimentando o corporativismo profissional: "Vem Sem-Terra, vem indígena, vêm professores... para eles é o modo mais rápido de resolver e para nós é transtorno", resume, questionando os diversos protestos que ocorrem na estrada e que resultam em uma fila gigantesca de caminhões parados. Por outro lado, é dele, também, a única crítica aos colegas, quando vários caminhoneiros, para romper 0 engarrafamento, utilizam o acostamento. "É um baita desrespeito de classe. Para mim, nem amor pela profissão tem... Como uma classe dessas vai conseguir respeito para brigar por alguma coisa?" E, dialoga com a produção (e com o público): "queriam emoção, queriam aventura? Conseguiram...”.

Esta estrutura narrativa, de diário, de autorreflexão do caminhoneiro, de inserção de infográfico, de inclusão de cenas em que a tecnologia moderna ganha espaço, vai se repetir, praticamente idêntica, nos outros episódios da temporada. As particularidades de cada protagonista são sempre destacadas dramaticamente, acentuando determinadas características do personagem e da viagem que realiza. Constrói-se, deste modo, um espectro bastante homogêneo em termos narrativos e estéticos e, por isso mesmo, a inclusão de Thaís da Silva (Figura 3), natural de São Bernardo do Campo, caminhoneira há seis anos, destaca-se. Com 1,47 metros de altura, ela costuma viajar em dupla com o marido, mas é sobre ela que 0 programa se volta. 0 subtexto do empoderamento 
Figura 3: A caminhoneira Thaís, na cabine onde se vê a referência às filhas.

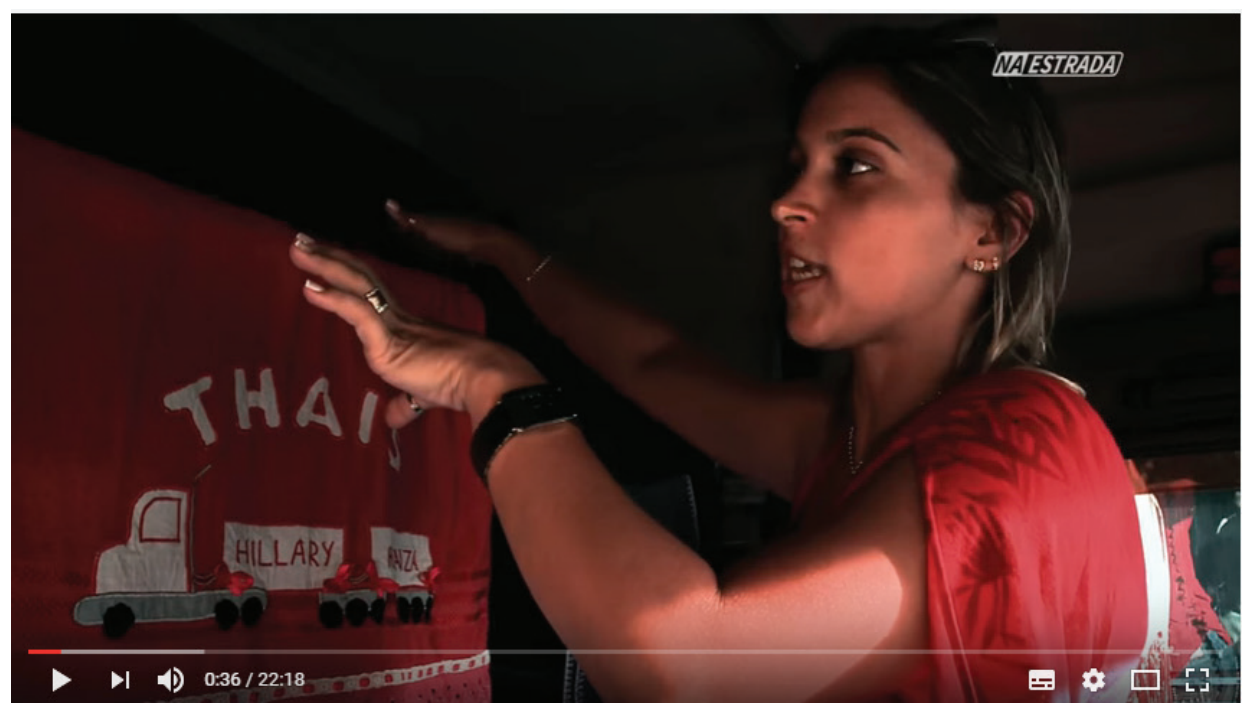

FONTE: Print do programa

feminino que poderia se desdobrar de tal protagonismo, alinhado à temática atual e relativamente surpreendente na profissã $0^{26}$, no entanto, submerge a trejeitos e falas típicas do clichê feminino, como a apresentação de Thaís se maquiando, reclamando dos pés sujos e se arrumando sempre diante de um espelho ${ }^{27}$. Como os outros caminhoneiros da série, ela também apresenta sua escolha profissional como um sonho acalentado desde a infância e com um desafio duplo, porque, além de ser mulher, teve que enfrentar, segundo ela, a descrença de todos em função da sua altura. A confissão é feita em tom emotivo, tanto quanto o encontro com as duas filhas pequenas e a confissão de suas metas de vida, nas cenas finais do episódio. Estas, claro, incluem sua decisão de continuar na estrada.
Identificados com títulos que mesclam o nome do protagonista à carga que carrega, os 13 episódios da temporada 2015 tomaram como eixo, para inserções de materiais informativos extras, aspectos relacionados às condições de produção e circulação dos produtos. Garantiram, deste modo, a presença de personagens imbricados no universo do agronegócio. A tática não encobriu o evidente diálogo que o programa estabelece com as matrizes que compõem o imaginário sobre o campo e também com as situações que a estrada carrega (pensando, agora, no gênero), o que provocou deslocamento da série da chave documental e aproximou-a das narrativas da teledramaturgia. Uma referência recente, no cenário brasileiro, é a série Carga Pesada, da Rede Globo, inspirada em Jorge, um Brasileiro, 
romance de 0swaldo França Júnior. Testada, primeiro, como um Caso Especial, Carga Pesada teve dois períodos de exibição: de 1979 a 81, com 24 episódios $^{28}$ e de 2003 a 07, quando acumulou 62 episódios. Nas duas versões manteve os protagonistas Pedro (Antônio Fagundes) e Bino (Stênio Garcia), como motoristas de um caminhão que percorreu o país e contribuiu para dar visibilidade ao profissional. Este, agora na versão do Agronegócio, tem como principal antagonista as condições péssimas das estradas brasileiras, situação creditada, sempre, ao descaso e à corrupção governamental. A retórica genérica tem como contraponto o discurso de eficiência do setor, veiculado no programa. Aqui, as referências ao agronegócio reforçam a qualidade de gestão do setor, sua vocação empreendedora e a aposta na eficácia da tecnologia, tríade que configura a modernização do campo e 0 aproxima da cidade.

Essas facetas ficam mais evidentes na temporada de 2016, que abandona a estrutura narrativa que ampliava a voz do caminhoneiro. 0 projeto, apresentado como totalmente reformulado, integra Pablo Valler à equipe. É ele que assume o papel de narrador, agora voz intradiegética que trafega na entonação típica dos rodeios, pontuando 0 que considera ser destaque de cada episódio. Sua presença em cena acentua o perfil jornalístico da série, que abre mais espaço para entrevistas, especialmente na sequência que foca o período pré-estrada. Também há inserção de conteúdos extras, apresentados com vinhetas, antecipando o que viria ocorrer no site do Canal, que agrega novos conteúdos atualizando os episódios e são, geralmente, resultantes da ação de marketing do Canal. A narrativa, nesses "extras", é construída com fotos e animação, artificializando o discurso e distanciando-o significativamente do tom mais subjetivo da temporada anterior, sustentado pelo acionamento de recursos das narrativas ficcionais, como já vimos. A percepção da premência de um discurso mais direto, da explicitação mais objetiva das cadeias que estruturam o agronegócio, bem como a inserção de posicionamentos políticos de relativo confronto à condução do governo federal naquele momento, exalta a situação política do país, naquele momento já encaminhada para a destituição da presidenta eleita ${ }^{29}$.

A identificação dos episódios também muda, consagrando uma estratégia mais vinculada

28 Vale ressalvar que, na primeira versão, a série, em plena Ditadura Militar, contou com um grupo de roteiristas que incluía alguns dos melhores e mais politizados dramaturgos brasileiros, como Gianfrancesco Guarnieri, Dias Gomes e Walter George Durst, o que implicou, em diversos episódios, focar temas como meninos de rua, tratamento violento destinado às prostitutas e 0 abandono socioeconômico do campo. Mas, apesar de incluir o rural nas viagens, a maior parte da série concentrava os conflitos nos perímetros urbanos, em uma perspectiva que localizava a estrada mais como elo entre as cidades. É possível assistir a quase todos os episódios da série no YouTube.

Eleita com 54 milhões de votos em 2014, Dilma Rousseff, presidente do país, é condenada pelo Senado Federal em 31 de agosto de 2016. 0 impeachment foi aprovado por 60 votos a favor e 20 contra, sem abstenção. Sua deposição levou Michel Temer, seu vice, ao cargo de presidente do Brasil. A deposição, na voz de Rousseff e de milhares de brasileiros e da imprensa estrangeira, não passou de um golpe de Estado. 
ao cotidiano do caminhoneiro: "Cuidados na Estrada", "Estresse no Ceasa" etc. No entanto, a maior alteração foi trabalhar apenas com seis caminhoneiros fixos, reduzindo pela metade o grupo da temporada anterior. Apesar desse dado, a perspectiva de "heróis" de uma causa justa é mantida, tanto quanto a ancoragem emocional nos laços familiares. No entanto, os encontros pessoais e os momentos marcados por confissões íntimas subjazem à maior presença do agronegócio, ao ponto de o último episódio da temporada apresentar a fábrica da MAN, patrocinadora do programa. 0 tom é didático, assentado na fórmula da prestação de serviços que detalha, particularmente, cuidados que se deve ter para que a vida útil do caminhão se estenda. A estética deste último episódio incorpora uma interatividade "fake", instaurada na tela em design de celular. Nesta circulam vídeos das famílias dos caminhoneiros, destacando-se situações prosaicas do cotidiano, como carinho em animais domésticos e troca de botijão de gás. Na última sequência, fecha-se um ciclo com uma dura crítica ao sistema aduaneiro no Brasil e às condições da estrada, incluindo os altos custos dos pedágios.

\section{Considerações Finais}

No sistema de segmentação da televisão brasileira, houve pouco espaço para a construção de um modelo que se distinguisse do que ocorre na TV aberta do país. Por isso mesmo, cada investimento que se revele mais consistente ou seja, apresentando durabilidade e produção própria - tem potencial para revelar os desenhos estruturais da sociedade brasileira que vive agora uma das suas mais graves crises políticas. Nesta perspectiva, compreender e localizar os movimentos de um setor tão celebrado como 0 agronegócio, que reconhece ser a televisão a mídia mais acionada hoje pelo homem do campo, oferece pistas significativas das mudanças que estão sendo configuradas no contexto nacional. Particularmente. Isso ocorre porque, olhando os espaços de representação institucional e política que 0 setor ocupa no país, verifica-se uma convergência de interesses que multiplica sua força e presença nas decisões de governo. Isso afeta a todos. No campo e na cidade. Ainda mais sob a nova compreensão que se tem quanto à impossibilidade de se demarcar fronteiras nítidas para cada um desses "territórios".

Não à toa, portanto, que políticos com ambições presidenciais, como Geraldo Alckmin, atual (2018) governador de São Paulo, publica na "Folha de São Paulo", em uma edição de domingo (ou seja, de maior circulação), artigo intitulado "Os desafios do agronegócio", que exalta a participação do estado no setor e 0 investimento do governo estadual em infraestrutura e outras políticas 
que procuram garantir maior rentabilidade no campo $^{30}$. Em outras palavras, há um movimento na mídia brasileira de valorização do setor, de torná-lo "pop", em uma versão que foca combinar, o máximo possível, uma cultura de valores cristalizados no Brasil do início do século XX às práticas de consumo que garantem um verniz de modernidade. É algo que se soma às iniciativas do próprio agronegócio, como vimos em $\mathrm{Na}$ Estrada - Vida de Caminhoneiro: distante dos embates, conflitos e assassinatos que emergem, continuamente, das disputas por terra no meio rural brasileiro, o programa trabalha na mesma chave da mídia hegemônica, que continuamente criminaliza os movimentos sociais enquanto se abstém, praticamente em uníssono, de questionar o papel do setor neste processo. Não bastasse, desenha seu herói envolvendo-o nos clichês perpetuados pelo audiovisual, em trajetória que aproxima o caminhoneiro do mundo rural, sem referenciar, nem levemente, insatisfações salariais ou com o preço do frete, algo que é essencial para a própria rentabilidade dos produtores, 0 que os colocaria, talvez muitas vezes, no papel de antagonistas do protagonista de $\mathrm{Na}$ Estrada.

Positivar o discurso e ignorar situações de confronto é afinar o diapasão à cantiga de um país pacífico, cordial e alegre. 0 programa do Canal Rural banha-se, fartamente, nesse rio, tanto quanto assume o discurso da formação pautado pela ideia da qualificação, "generosamente" assumida pelo patronato brasileiro na versão do sistema $S$. Esse conhecimento, no entanto, parece alinhar-se, exclusivamente, às tradicionais representações do campo, que consolidaram um imaginário maniqueísta e distante dos embates que envolvem os vários personagens que o habitam ou o percorrem - como é o caso do caminhoneiro. Reforça, deste modo, a percepção de que, ao agronegócio e à mídia que o (re)inventa, estão destinados o papel de conviver com informações espetaculares, assentadas nas estruturas melodramáticas. que ratificam um universo sem espaço para vivências cidadãs, atuando no sentido de edulcorar a capacidade de argumentação de seus telespectadores.

Nesta vereda, destacar a figura do caminhoneiro em uma chave que reforça seu isolamento, seu perfil de herói, sua dedicação ao trabalho sem questionamentos aos patrões, enfim, sua vida tão específica e diferenciada, corrobora as distâncias que 0 urbano acredita ter do campo, em uma pauta que, de algum modo, torna-se ironicamente antagônica à mensagem de aproximação dos mundos, fabulada pela campanha da Rede Globo. Na solidão da cabine e no reforço melodramático dos desafios a vencer para se chegar aos locais identificados como pertencentes ao "Brasil profundo", o caminhoneiro das temporadas 2015 e 2016 de Na Estrada mantém o Brasil real impossível de ser, no mínimo, percebido em suas tensões e complexidades, o que poderia, quem sabe, levar não só a um novo olhar do urbano sobre o rural, mas também permitir que todos percebam 0 quanto o rural impacta 0 amplo território brasileiro. 0 que sobra, portanto, é esta 
espécie de olheiro privilegiado - 0 caminhoneiro - que é capaz de identificar os diversos entraves que persistem na realidade brasileira e que são nomeados na série, não raro, como resultantes, apenas e estrategicamente, das más gestões dos governos. Considerando a época da realização das duas temporadas - 2015 e 2016 - tudo indica que não há nada de inocente em tal discurso midiático.

\section{Referências}

ALCKMIN, Geraldo. "Os desafíos do Agronegócio". In Folha de São Paulo, 19/02/2017. Disponível em: http:// wwwl.folha.uol.com.br/opiniao/2017/02/1859952-osdesafios-do-agronegocio.shtml (Acesso em 19/02/2017).

ALVES, Marcio Moreira. Histórias do Brasil Profundo. Rio de Janeiro: Nova Fronteira, 2003.

AUMONT, Jacques; MARIE, Michel. A Análise do Filme. $2^{\mathrm{a}}$ ed. Lisboa: Edições Texto \& Grafia Ltda. BARRETO, Virgínia Sá. Comunidades Simbólicas - Identificação Imaginária, Pactos e Vínculos em Telejornalismo. João Pessoa: Editora UFPB, 2013. BARROS, Antônio Teixeira de. "0 rural midiatizado: análise comparada Brasil-Portugal". In Ambient.soc. vol.18.n 3. São Paulo jul/Set 2015. Disponível em: http:// www.scielo.br/scielo.php?script $=$ sci_arttext\&pid $=$ S1414753X2015000300003 (Acesso em 18/03/2016)

BLUME, Roni. Território e ruralidade: A desmistificação do fim do rural. Porto Alegre: FCE, 2004.

BOURDIEU, Pierre. A ilusão biográfica. In Ferreira, Marieta de Moraes \& AMAD0, Janaína (Orgs). Usos

\& Abusos da História Oral. $8^{\mathrm{a}}$ Ed. Rio de Janeiro: Editora FGV, 2006.

CAMPBELL, 0 herói de mil faces. São Paulo: Editora Pensamento, 1989.
COHAN, Steven and HARK, Ina Rae (Ed.). The Road Movie Book. London/New York: Routledge, 1997. DAHER, José. 100 anos depois - A história de Mazzaropi. São Paulo: Editora Nelpa: 2013.

G1 - "Agronegócio é valorizado em campanha da Rede Globo. (s/a). Publicada em 01/10/2016 e atualizada em 03/10/2016. Disponível em: http://g1.globo.com/ economia/agronegocios/agro-a-industria-riqueza-dobrasil/noticia/2016/10/agronegocio-e-valorizado-emcampanha-da-rede-globo.html (Acesso em 20/12/2016) GONZAGA, Adhemar; SALLES, P.E. 70 anos de Cinema Brasileiro. São Paulo: Editora Expressão e Cultura S.A., 1966.

MENDES, J.T.G.; PADILHA JR., J.B. Agronegócio: uma abordagem econômica. São Paulo: Pearson Prentice Hall, 2007.

NICHOLS, Bill. A voz do documentário. In RAMOS, Fernão Pessoa (Org.). Teoria Contemporânea do Cinema - Documentário e narratividade ficcional - Vol. II. São Paulo: Senac, 2005.

PAIVA, Samuel. "Dimensões Transculturais do Gênero Audiovisual - Argumentos para um a pesquisa sobre o filme de estrada". Texto apresentado ao Grupo de Trabalho Cultura das Mídias, do XVII Encontro do Compós, na UNIP, São Paulo, SP, em junho de 2008. Disponível em: http://www.compos.org.br/pagina.php?m enu $=8 \& \mathrm{mmenu}=\&$ ordem $=2 \&$ grupo $1=9 \mathrm{D} \&$ grupo $2=1$ $1 \&$ encontro $=\& \operatorname{tag}=\& a n 0=\&$ mes $=\&$ phave $=\&$ git $=\&$ $\mathrm{pg}=18$. (Acesso em 20/10/2016)

PEREIRA, Reinaldo Maximiano. "Diálogos entre os Estudos de Televisão e os Estudos Visuais: a terra na obra de Benedito Ruy Barbosa e a busca por uma metodologia de análise televisual. Anais da Compós, 2015. Disponível em: http://www.compos.org.br/ biblioteca/compos-2015-3f1fc66d-fb0b-4e06-84d77ce2e7c4f9e7_2871.pdf (Acesso em 20/11/2016) REIS, Douglas Sathler dos. "0 Rural e o Urbano no Brasil”. Trabalho apresentado no XV Encontro 
Nacional de Estudos Populacionais, ABEP, realizado em Caxambu-MG - Brasil, de 18 a 22 de setembro de 2006.

SANTOS, André Marenco. "Topografia do Brasil profundo: votos, cargos e alinhamentos nos municípios brasileiros". Revista Opinião Pública, v. 19, $\mathrm{n}^{0}$ 1, junho de 2013, Campinas/SP, s/p. Disponível em http://www.scielo.br/scielo.php?script=sci arttext\&pid $=$ S0104-62762013000100001 (Acesso em 18/05/2017).

SILVA, José Graziano. 0 novo rural Brasileiro. Belo Horizonte: Ed. Nova Economia, 1997.

TAVARES, Denise. Vida longa ao curta. Dissertação de Mestrado. Instituto de Arte/Unicamp, 1999 . As viagens de Salles, Solanas e Sarquis. Tese de Doutorado. Prolam/USP, 2009.

TAVARES, Maria José de Castro Souza. "Produção em Telejornalismo Rural: um estudo de caso sobre o Programa Globo Rural”. Dissertação de Mestrado. Universidade de Marília (UNIMAR), 2008.

VELLOSO, João Paulo dos. Rumo ao Brasil Desenvolvido - em Duas, Três Décadas. Rio de Janeiro: Campus - Elsevier, 2012. 


\section{Agro is pop: the truckers} of On the Road in the context of "new Brazilian rural"

\section{Abstract}

This work analyzes On the Road - the Life of a Truck Driver, a TV show aired by Rural Channel, focusing on the meanings and language strategies it produced over two distinct seasons. Also, it is concerned with how the project relates to certain matrices of the Imaginary assumed by the television media regarding the rural environment and what dialogues it engages in with the valorization movement of the Agribusiness in the context of the new Rural Brazil. Centered on the trucker, "On the Road" reworks features of the "road-movie" genre and seeks to update the discourse of the unknown Brazil "that works", thus reinforcing a homogeneous and schematic view of the Brazilian countryside, hiding its complex reality from the the urban world.

\section{Keywords}

Television. On the Road - Truck Driver's Life. Agribusiness

\section{Agro es pop: los camioneros de En la Carretera en el contexto del "nuevo rural brasileño"}

\section{Resumen}

Este trabajo analiza En la Carretera - Vida de Camionero, del Canal Rural, buscando demostrar los sentidos del programa y sus estrategias de lenguaje en dos temporadas distintas. También busca ver como el proyecto se relaciona con determinadas matrices del imaginario asumidos por los medios televisivos sobre el medio rural y que diálogos establece con el movimiento de valorización del agronegocio en el contexto del "nuevo rural brasileño". En En la Carretera, el foco en el camionero retrae las características del "road movie" y busca actualizar el discurso del Brasil desconocido "que funciona". Refuerza así una visión homogénea y esquemática del campo, manteniendo su realidad compleja distante de la percepción del mundo urbano.

\section{Palabras-clave}

Televisión. En la carretera - Vida de Camionero. Agronegocios 


\section{Expediente}

A revista E-Compós é a publicação científica em formato eletrônico da Associação Nacional dos Programas de Pós-Graduação em Comunicação (Compós). Lançada em 2004, tem como principal finalidade difundir a produção acadêmica de pesquisadores da área de Comunicação, inseridos em instituições do Brasil e do exterior.

\section{E-COMPÓS I www.e-compos.org.br I E-ISSN 1808-2599}

Revista da Associação Nacional dos Programas de Pós-Graduação em Comunicação. Brasília, v.21, n.2, maio/ago. 2018. A identificação das edições, a partir de 2008, passa a ser volume anual com três números. Indexada por Latindex I www.latindex.unam.mx

\section{CONSELHO EDITORIAL}

Ada Cristina Machado Silveira, Universidade Federal de Santa Maria, Brasil Alda Cristina Silva da Costa, Universidade Federal do Pará, Brasil Alfredo Luiz Paes de Oliveira Suppia, Universidade Estadual de Campinas, Brasil Ana Regina Barros Rego Leal, Universidade Federal do Piauí, Brasil Ana Carolina Rocha Pessôa Temer, Universidade Federal de Goiás, Brasil André Luiz Martins Lemos, Universidade Federal da Bahia, Brasil Angela Cristina Salgueiro Marques, Universidade Federal de Minas Gerais, Brasil Ângela Freire Prysthon, Universidade Federal de Pernambuco, Brasil Anna Cristina Pertierra, Western Sidney University - Australia Antonio Carlos Hohlfeldt, Pontifícia Universidade Católica do Rio Grande do Sul, Brasil Arthur Ituassu, Pontifícia Universidade Católica do Rio de Janeiro, Brasil Bruno Campanella, Universidade Federal Fluminense, Brasil Bushra Rahman, University of the Punjab, Paquistão Cláudio Novaes Pinto Coelho, Faculdade Cásper Líbero, Brasil Cárlida Emerim, Universidade Federal de Santa Catarina, Brasil Carlos Del Valle Rojas, Universidad de La Frontera, Chile Carlos Eduardo Franciscato, Universidade Federal de Sergipe, Brasil Danilo Rothberg, Universidade Estadual Paulista, Brasil Denise Tavares da Silva, Universidade Federal Fluminense, Brasil Diógenes Lycarião, Universidade Federal do Ceará, Brasil Doris Martines Vizcarrondo, Universidad de Porto Rico, Porto Rico Eduardo Vicente, Universidade de São Paulo, Brasil Eliza Bachega Casadei, Escola Superior de Propaganda e Marketing - SP, Brasil Elvira Gomes dos Reis, Universidade do Cabo Verde, Cabo Verde Eneus Trindade, Universidade de São Paulo, Brasil Erick Felinto de Oliveira, Universidade do Estado do Rio de Janeiro, Brasil Erick Torrico, Universidad Andina Simón Bolívar, Bolívia Erly Vieira Júnior, Universidade Federal do Espírito Santo, Brasil Fabio La Rocca, Université Paul Valéry Montpellier III, França Fernando Firmino da Silva, Universidade Federal da Paraíba, Brasil Francisco de Assis, FIAM-FAAM Centro Universitário, Brasil Francisco Elinaldo Teixeira, Universidade Estadual de Campinas, Brasil Francisco Gilson R. Pôrto Jr., Universidade Federal do Tocantins, Brasil Francisco Sierra Caballero, Ciespal, Equador

Frederico de Mello Brandão Tavares, Universidade Federal de Ouro Preto, Brasil Gabriela Reinaldo, Universidade Federal do Ceará, Brasi Gérman Rey, Pontifícia Universidad Javeriana, Colômbia Gilson Vieira Monteiro, Universidade Federal do Amazonas, Brasil Gustavo Daudt Fischer, Universidade do Vale do Rio dos Sinos, Brasil Gustavo Hernández Díaz, Universidad Central de Venezuela, Venezuela Heidi Figueroa Sarriera, Universidad de Puerto Rico, Porto Rico Ignacio Aguaded, Universidad Huelva, Espanha

Inesita Soares de Araújo, FIOCRUZ, Brasil Itania Maria Mota Gomes, Universidade Federal da Bahia, Brasil Jiani Adriana Bonin, Universidade do Vale do Rio dos Sinos, Brasil João Carlos Correia, Universidade de Beira Interior, Portugal Jonathan Cohen, da University of Haifa, Israel José Afonso da Silva Junior, Universidade Federal de Pernambuco, Brasil José Luiz Aidar Prado, Pontifícia Universidade Católica de São Paulo, Brasil Josette Maria Monzani, Universidade Federal de São Carlos, Brasil Juçara Gorski Brittes, Universidade Federal de Ouro Preto, Brasil Julián Durazo Herrmann, Université du Québec à Montréal Juliana Freire Gutmann, Universidade Federal da Bahia, Brasil
Karla Covarrubias, Universidad de Colima, México Laura Loguercio Cánepa, Universidade Anhembi Morumbi, Brasil Leonel Azevedo de Aguiar, Pontifícia Universidade Católica do Rio de Janeiro, Brasi Letícia Cantarela Matheus, Universidade do Estado do Rio de Janeiro, Brasil Ling Chen, Hong Kong Baptist University Luciana Coutinho Souza, Universidade de Sorocaba, Brasil Maria Ataide Malcher, Universidade Federal do Pará, Brasil Maria Elena Hernández Ramírez, Universidad de Guadalajara, México Maria Elisabete Antonioli, Escola Superior de Propaganda e Marketing - SP, Brasil Maria das Graças Pinto Coelho, Universidade Federal do Rio Grande do Norte, Brasil Maria Teresa Quiroz, Universidad de Lima, Peru Marialva Carlos Barbosa, Universidade Federal do Rio de Janeiro, Brasil Marina Poggi, Universidad Nacional de Quilmes, Argentina Marcel Vieira Barreto Silva, Universidade Federal da Paraíba, Brasil Marcia Tondato, Escola Superior de Propaganda e Marketing, Brasil Marli Santos, Universidade Metodista de São Paulo, Brasil Márcio Souza Gonçalves, Universidade do Estado do Rio de Janeiro, Brasil Mateus Yuri Passos, Universidade Metodista de São Paulo, Brasil Mauricio Mario Monteiro, Universidade Anhembi Morumbi, Brasil Mayka Castellano, Universidade Federal Fluminense, Brasil Mirna Varela, Universidad de Buenos Aires, Argentina Mozahir Salomão Bruck, Pontifícia Universidade Católica de Minas Gerais, Brasil Neyla Pardo, Universidad Nacional de Colombia, Colombia Nísia Martins Rosario, Universidade Federal do Rio Grande do Sul, Brasil Olga Guedes Bailey, Nottingham Trent University, Inglaterra Paolo Demuru, Universidade Paulista, Brasil Paolo Peverini, L.O.U.I.S.S de Roma, Itália

Paško Bilić, Institute for Development and International Relations, Croácia Paula Melani Rocha, Universidade Estadual de Ponta Grossa, Brasil Potiguara Mendes Silveira Jr, Universidade Federal de Juiz de Fora, Brasil Priscila Ferreira Perazzo, Universidade Municipal de São Caetano do Sul, Brasil Rafael Cardoso Sampaio, Universidade Federal do Paraná, Brasil Rafael Tassi Teixeira, Universidade Tuiuti do Paraná, Brasil Regiane Lucas Garcês, Universidade Federal de Minas Gerais, Brasil Regiane Regina Ribeiro, Universidade Federal do Paraná, Brasil Renata Pitombo Cidreira, Universidade Federal do Recôncavo da Bahia, Brasil Renato Essenfelder, Escola Superior de Propaganda e Marketing, Brasil Roberto Elísio dos Santos, Universidade Municipal de São Caetano do Sul, Brasil Robson Borges Dias, Universidade Católica de Brasília (UCB), Brasil Rodolfo Rorato Londero, Universidade Estadual de Londrina, Brasil Rosario Sánchez Vilela, Universidad Católica del Uruguay, Uruguai Roseli Figaro, Universidade de São Paulo, Brasil

Saima Saeed, Jamia Millia Islamia, India Sara Brandelero, Leyden University, Holanda

Simone Maria Andrade Pereira de Sá, Universidade Federal Fluminense, Brasil Sônia Caldas Pessoa, Universidade Federal de Minas Gerais, Brasil Sun Sun Lim, Singapore University of Technology and Design, Singapura Tatiana Oliveira Siciliano, Pontifícia Universidade Católica do Rio de Janeiro, Brasil Thaïs de Mendonça Jorge, Universidade de Brasília, Brasil Valquiria Michela John, Universidade Federal do Paraná, Brasil Vicki Mayer, Tulane University, Estados Unidos Yamile Haber Guerra, Universidad de Oriente, Cuba 


\section{CONSELHO CIENTÍFICO}

Cristiane Freitas Gutfreind, Pontifícia Universidade Católica do Rio Grande do Sul, Brasil I Eduardo Antônio de Jesus, Universidade Federal de Minhas Gerais, Brasil | Eduardo Morettin, Universidade de São Paulo, Brasil I Irene de Araújo Machado, Universidade de São Paulo, Brasil | Miriam de Souza Rossini, Universidade Federal do Rio Grande do Sul, Brasil

\section{COMISSÃO EDITORIAL}

Igor Pinto Sacramento, Universidade Federal do Rio de Janeiro, Brasil । Kelly Cristina de Souza Prudencio, Universidade Federal do Paraná, Brasil । Osmar Gonçalves dos Reis Filho, Universidade Federal do Ceará, Brasil I Rafael Grohmann, Faculdade Cásper Líbero, Brasil I Thaiane Moreira de Oliveira, Universidade Federal Fluminense, Brasil (editores associados)

\section{CONSULTORES AD HOC}

Alessandro Constantino Gamo, Universidade Federal de São Carlos (UFSCAR) | Amanda Mauricio Pereira Leite, Universidade Federal do Tocantins (UFT) | Amílcar Almeida Bezerra, Universidade Federal de Pernambuco (UFPE) I Ana Carolina Damboriarena Escosteguy, Universidade Federal de Santa Maria (UFSM) I Ana Luiza Coiro Moraes, Faculdade Cásper Líbero | Antonio Pacca Fatorelli, Universidade Federal do Rio de Janeiro (UFRJ) | Ariane Diniz Holzbach, Universidade Federal Fluminense (UFF) I Benjamin Picado, Universidade Federal Fluminense (UFF) I César Augusto Baio dos Santos, Universidade Federal do Ceará (UFC) I César Geraldo Guimarães, Universidade Federal de MInas Gerais (UFMG) I César Ricardo Siqueira Bolaño, Universidade de Brasília (UNB) I Ciro Marcondes Filho, Universidade de São Paulo (USP) I Felipe Simão Pontes, Universidade Estadual de Ponta Grossa I Felipe Trotta, Universidade Federal Fluminense (UFF) I Gislene da Silva, Universidade Federal de Santa Catarina (UFSC) I Kati Caetano, Universidade Tuiuti do Paraná I Laan Mendes de Barros, Universidade Estadual Paulista Júlio de Mesquita Filho I Lucia Leão, Pontifícia Universidade Católica de São Paulo (PUC-SP) I Jairo Getulio Ferreira, Universidade do Vale do Rio dos Sinos (UNISINOS) | Juliana Doretto, FIAM-FAAM | Juliano Maurício de Carvalho, Universidade Estadual Paulistaa Júlio de Mesquita Filho | Lilian Cristina Monteiro França, Universidade Federal de Sergipe I Liziane Soares Guazina, Universidade de Brasília (UNB) I Luís Mauro Sá Martino, Faculdade Cásper Líbero I Luiz Peres Neto, Escola Superior de Propaganda e Marketing (ESPM) I Herom Vargas, Universidade Metodista de São Paulo I Inês Silvia Vitorino Sampaio, Universidade Federal do Ceará (UFC) I Maria Helena Weber, Universidade Federal do Rio Grande do Sul (UFRGS) I Mariana Baltar, Universidade Federal Fluminense (UFF) I Maurício de Bragança, Universidade Federal Fluminense (UFF) I Mauro de Souza Ventura- Universidade Estadual Paulista Júlio de Mesquita Filho I Muniz Sodre de Araujo Cabral, Universidade Federal do Rio de Janeiro (UFRJ) I Nuno Manna, Universidade Federal da Bahia (UFBA) I Rosana de Lima Soares, Universidade de São Paulo (USP) I Sandra Maria Lúcia Pereira Gonçalves, Universidade Federal do Rio Grande do Sul (UFRGS) I Sérgio Luiz Gadini, Universidade Estadual de Ponta Grossa I Talitha Gomes Ferraz, Escola Superior de Propaganda e Marketing (ESPM) I Victa de Carvalho Pereira da Silva, Universidade Federal do Rio de Janeiro (UFRJ)

\section{EQUIPE TÉCNICA}

ASSISTENTES EDITORIAL Melina Santos | REVISÃO DE TEXTOS Fátima Áli | EDITORAÇ̃̃o ELETRÔNICA Roka Estúdio

COMPÓS I www.compos.org.br

Associação Nacional dos Programas de Pós-Graduação em Comunicação

Presidente

Marco Roxo

Programa de Pós-Graduação em Comunicação - UFF marcos-roxo@uol.com.br

Vice-Presidente

Isaltina Gomes

Programa de Pós-Graduação em Comunicação - UFPE

isaltina@gmail.com

Secretária-Geral

Gisela Castro

Programa de Pós-Graduação em Comunicação

e Práticas de Consumo - ESPM

castro.gisela@gmail.com

CONTATO I revistaecompos@gmail.com 